\title{
COMMENTS FROM THE EDITORS
}

\section{HAS THE PENDULUM SWUNG TOO FAR?}

In this issue of the Journal there are new guidelines for the use of statistics in prospective manuscripts submitted to the Journal. They are in agreement with the "Uniform Requirements for Manuscripts Submitted to Biomedical Journals" published in the Annals of Internal Medicine.

Biostatistics has become an ever more important component of biomedical research and, in the past, statisticians have criticized journals for lack of statistical rigor. Thus, in January, the Journal initiated guidelines that were to aid the author and expedite the review process. Some authors have perceived them as too rigid and coercive. In light of these comments, we have rewritten the guidelines with the hope that they will be more "user friendly," still

Copyright (C) 1998 by Mosby, Inc.

0022-5223/98 \$5.00+ $0 \quad \mathbf{1 2 / 1 / 9 1 6 6 5}$ maintaining statistical standards. We also recognize the unique aspect of surgical research in which randomization is difficult and obviously nonblinded. Numbers are often small both in clinical trials and in animal experiments where availability or cost can become prohibitive when larger numbers are demanded in order to meet the stringent requirements of some biostatisticians.

Biostatistical review remains essential to elicit the true differences in results between two or more groups. It will be our aim to find the pathway between the extremes so that authors and readers will have reasonable confidence in the conclusions presented without going through a biostatistical "inquisition." We will try to bring the pendulum back to center.

Eugene H. Blackstone, MD John A. Waldhausen, MD 